\title{
MERCADO DE TRABALHO E SALÁRIO MÍNIMO NA CHINA
}

Resumo: Este artigo analisa a evolução da política de salário mínimo na China desde o estabelecimento da "sociedade harmoniosa" do ex-presidente Hu Jintao e durante o atual "sonho chinês" de Xi Jinping, examinando-a no contexto geral de funcionamento do mercado de trabalho chinês. A elevada heterogeneidade no desenvolvimento socioeconômico do país está por trás da relativa complexidade da política de salários mínimos na China, onde não existe um dado oficial de mínimo nacional tal como no Brasil. Diante disso, esse artigo contribui empiricamente para o debate ao desenvolver um cálculo próprio do salário mínimo nacional na China de forma a discutir sua variação regional e seus potenciais efeitos na distribuição de renda nacional.

Palavras-chave: China. Mercado de trabalho. Salário mínimo. Sonho chinês. Sociedade harmoniosa.

\section{LABOR MARKET AND MINIMUM WAGE IN CHINA}

Abstract: This article analyzes the evolution of the minimum wage policy in China since the establishment of an "harmonious society" with ex-president Hu Jintao's and during Xi Jinping's current "Chinese dream", examining it in the general context of the functioning of the Chinese labor market. The high heterogeneity in the country's socioeconomic development is behind the relative complexity of the minimum wage policy in China, making a direct concept of a national minimum such as in Brazil unviable. In this sense, this article contributes empirically to the debate by developing its own estimation of the national minimum wage in China in order to discuss its regional variation and its potential effects on national income distribution.

Keywords: China. Labor market. Minimum wage. Chinese dream. Harmonious society.

\section{MERCADO LABORAL Y SALARIO MÍNIMO EN CHINA}

Resumen: Este artículo analiza la evolución de la política de salario mínimo en China desde el establecimiento de la "sociedad armoniosa" del ex presidente Hu Jintao y durante el "sueño chino" actual de Xi Jinping, examinándola en el contexto general del funcionamiento del mercado laboral chino. La alta heterogeneidad en el desarrollo socioeconómico del país está detrás de la relativa complejidad de la política de salario mínimo en China, lo que hace que el concepto directo de un mínimo nacional como en Brasil sea inviable. Dado esto, este artículo contribuye empíricamente al debate al

\footnotetext{
${ }^{1}$ Universidade Federal do Rio de Janeiro (UFRJ), Instituto de Economia, Programa de Pós-Graduação em Economia Política Internacional, Laboratório de Estudos em Economia Política da China (LabChina), Rio de Janeiro, Brasil, jpedrolbraga@gmail.com, 0000-0002-4599-1712

2 Universidade Federal do Rio de Janeiro (UFRJ), Instituto de Economia, Programa de Pós-Graduação em Economia Política Internacional, Laboratório de Estudos em Economia Política da China (LabChina), Rio de Janeiro, Brasil, isabela.nogueira@ie.ufrj.br, 0000-0001-8223-7906
} 
desarrollar su propio cálculo del salario mínimo nacional en China para discutir su variación regional y sus posibles efectos sobre la distribución del ingreso nacional.

Palabras clave: China. Mercado laboral. Salario mínimo. Sueño chino. Sociedade armoniosa.

\section{Introdução}

Depois de décadas sendo caracterizada como chão de fábrica global - ou como um país marcado por custos baixos de produção, mão-de-obra barata e um mercado de trabalho selvagem -, a China avança no século XXI em uma completa nova dinâmica. O chão de fábrica subiu nas cadeias de valor e hoje a China é, acima de tudo, o maior desafio tecnológico e produtivo às potências inovativas estabelecidas. Também a era da mão de obra barata acabou, e um estudo da consultoria Euromonitor International aponta que, em 2016, o salário médio da indústria chinesa já superava os valores pagos aos trabalhadores no Brasil e no México e estava se aproximando rapidamente aos recebidos em Grécia e Portugal. Entre 2005 e 2016, os salários por hora na indústria chinesa triplicaram para US\$3,60, segundo a Euromonitor. Nesse período, os salários industriais caíram de US\$ 2,90 para US\$ 2,70 no Brasil (China Economic Review, 2017).

Esse artigo contribui para o entendimento de transformações tão colossais ao lançar luz a uma instituição que, como boa parte das instituições chinesas, se modificou profundamente nos últimos 40 anos: o mercado de trabalho. Para além do aumento expressivo dos salários, vamos explorar a crescente institucionalização desse mercado, com intervenções diretas do Estado para minimizar as disputas capital/trabalho, para influir na mudança do padrão de crescimento e para efetivar a constituição de um Estado de bem-estar social ampliado.

Um dos mecanismos que permite articular a interação entre os objetivos de mediação do conflito distributivo, mudança padrão de crescimento e consolidação Estado de bem-estar é a existência de uma política ativa de determinação de salários mínimos. A magnitude dos efeitos do salário mínimo depende tanto do desenho da política quanto da institucionalidade do mercado de trabalho e da conjuntura econômica na qual a valorização ocorre. No entanto, dentre as várias funções que o salário mínimo desempenha em uma economia de mercado regulada, seu papel é absolutamente 
essencial para os assalariados mais precarizados, ou para trabalhadores cujo poder de barganha é estruturalmente débil.

Mas afinal, como tem evoluído o salário mínimo na China desde o estabelecimento da "sociedade harmoniosa" do ex-presidente Hu Jintao e durante o atual "sonho chinês" de Xi Jinping? A elevada heterogeneidade no desenvolvimento socioeconômico do país está por trás da relativa complexidade da política de salários mínimos na China, uma vez que eles são determinados provincialmente e isso inviabiliza um cálculo direto de mínimo nacional. Dessa forma, é necessário desenvolver uma metodologia de estimação do salário mínimo nacional a partir dos dados provinciais de forma a proporcionar uma melhor compreensão da evolução dessa variável ao longo dos dois períodos em questão. De posse dessa metodologia, foi possível extrair importantes observações sobre a relevância do salário mínimo como variável distributiva de reequilíbrio da distribuição de renda nacional no período da sociedade harmoniosa, enquanto durante sonho chinês houve uma perda real sensível dos salários mínimos frente aos salários médios.

A próxima seção apresenta o arcabouço teórico em torno do papel do salário mínimo no mercado de trabalho e no desenvolvimento socioeconômico nacional. A seção três apresenta o próprio funcionamento e institucionalidade do mercado de trabalho na China, enquanto a seção quatro discute seu papel na transição para um padrão de acumulação liderado pelas inovações e baseado no consumo, assim como na consolidação de um Estado de bem-estar social. A seção cinco traz nossa contribuição empírica ao debate sobre a evolução dos mínimos na China, materializada no cálculo de um salário mínimo nacional que permite examinar seu comportamento em relação ao salário médio e sua variação regional. A última seção sumariza nossas conclusões.

\section{Notas teóricas sobre o salário mínimo}

A necessidade de um piso político para os salários dialoga fortemente com a concepção de Polanyi (2000) do trabalho enquanto mercadoria fictícia. Usando o conceito de mercadoria fictícia para destacar a tensão as contradições de um mercado de trabalho desregulado, Polanyi aponta que a redistribuição pelo Estado é um aspecto vital da institucionalização econômica na consolidação de estruturas de mercado de 
trabalho. Nessa perspectiva, esse mercado deve ser construído socialmente de acordo com as normas de justiça vigentes de forma a evitar uma comoditização da força de trabalho por meio de instituições redistributivas de proteção social (BUGRA, A.; AGARTAN; BUGRA, 2007; PATON, 2010). Destarte, os salários mínimos devem ser analisados como instituição central do mercado de trabalho, refletindo a história política de uma sociedade.

O salário mínimo, como instrumento de intervenção no mercado de trabalho cujo objetivo é estabelecer um piso legal de remuneração ao trabalho, é uma instituição antiga, datando do final do século XIX na Nova Zelândia. No entanto, sua aplicação em escala mundial só se intensificou a partir da resposta à crise de 1929 - ao ponto que em 2009 cerca de 90\% dos países adotava alguma política de salário mínimo (HERR et al., 2009). Como toda política pública, há inúmeros desenhos de mínimos - horários, mensais, regionais, nacionais, setoriais - tal como há muitos canais pelos quais eles afetam o mercado de trabalho e têm consequências sobre renda, emprego e preços na economia.

Tal como a própria aplicação do salário mínimo, o debate teórico sobre seus efeitos no mercado de trabalho foi fortemente influenciado pela história do pensamento econômico. Isso, pois seus efeitos dependem essencialmente da teoria de formação de salários adotada e, mesmo que não havendo uma sistematização formal teórica desenvolvida, os impactos do mínimo são consequências indiretas dos pressupostos do mercado de trabalho. Historicamente, o paradigma neoclássico e suas diversas variantes dominam os debates teóricos com suas conclusões estáticas e naturalizadas de uma economia de mercado. No entanto, abordagens heterodoxas questionam fortemente essa dominância a partir de fatos estilizados do mercado de trabalho que apontam para a inconsistência dos pressupostos neoclássicos de informação e competição perfeitas.

De forma geral, o modelo neoclássico padrão chega à conclusão de que o aumento dos salários mínimos aumenta o desemprego e reduz lucros, dado que os determinantes do nível de emprego e produção são as condições do lado da oferta. Assim, uma elevação do salário mínimo só teria efeitos distributivos de forma indireta, ao reduzir o emprego em postos de trabalho de menor qualificação - sendo concentradora de renda (CAHUC, 2004). Nesse sentido, a orientação de política é que 
governos não devem introduzir salários mínimos para evitar esses efeitos. Embora haja um reconhecimento na literatura mainstream sobre os efeitos positivos do mínimo na redução da pobreza (ILO, 2009; LEE; SOBECK, 2012; LEMOS, 2009), a influência do salário mínimo sobre a remuneração do trabalho pouco qualificado é incompatível com a suposição neoclássica de determinação salarial pela produtividade marginal do trabalho. No entanto, é importante destacar que esse pressuposto ainda exerce forte influência nos modelos contemporâneos - mesmo estes admitindo influência distributiva.

Do ponto de vista keynesiano clássico, tendo como principal motor do emprego a demanda efetiva, aumentos nos salários mínimos não teriam efeitos sistemáticos no emprego - nem positivos, nem negativos. É importante ressaltar que essa interpretação resulta de uma aplicação do princípio da demanda efetiva em acordo com os póskeynesianos, não estando presente formalmente nos trabalhos de Keynes (HEISE, 2017). Nas perspectivas pós-keynesiana e estruturalista, para que uma valorização seja eficaz do ponto de vista distributivo é necessário que os mínimos interajam com a estrutura heterogênea ou segmentada do mercado de trabalho: afetando uma parcela significativa dos trabalhadores, sendo frequentemente ajustados para repor a inflação e alguma medida de produtividade e, por último, afetando a estrutura de rendimentos do trabalho - devendo crescer mais que o salário médio da economia (HERR et al., 2009). Assim, valorizações moderadas teriam importante efeito distributivo sem desemprego.

Adicionalmente, ao longo do século XX, correntes teóricas institucionalistas e estruturalistas argumentaram que modelos neoclássicos não correspondem à realidade do mercado de trabalho. Isso, pois esses mercados são caracterizados por assimetrias que justificam a intervenção do Estado via regulação do piso salarial, alterando a estrutura do mercado. Dessa forma, a institucionalização do mínimo impõe um piso abaixo do qual se considera a remuneração do trabalho insuficiente para uma vida digna, constituindo uma negociação política coletiva para trabalhadores cujo poder de barganha é estruturalmente débil (MEDEIROS, 2015; MICHAEL PIORE, 1979). Piore (1979) ressalta a importância do salário mínimo no contexto de mercados de trabalho fortemente segmentados, sendo recebidos por grupos mais vulneráveis e ocupados em uma estrutura de "mercado de trabalho secundário" - onde predominam os baixos salários e alta rotatividade. Do ponto de vista da determinação dos salários, nesse 
esquema analítico o salário mínimo constitui uma referência essencial para assalariados do mercado de trabalho secundário - ancorando a remuneração (MEDEIROS, 2015).

De maneira análoga, podendo o salário mínimo aumentar o poder de barganha do trabalhador, ele teria efeitos macroeconômicos de estabilização - sendo possível que sua valorização aumente a eficiência econômica mesmo em situação de competição perfeita (KAUFMAN, 2010). No início dos anos 90, estimulado pelos aumentos dos mínimos nos Estados Unidos, o debate sobre seus efeitos distributivos ganhou impulso com a New Minimum Wage Research. Nesse paradigma, o modelo de monopsônio dinâmico oferece um mecanismo importante para explicar os efeitos distributivos do mínimo: quando defrontados com um mercado de trabalho não competitivo, os empregadores podem, diante do aumento do piso salarial, reduzir custos de rotatividade na contratação em vez de diminuir o volume de emprego (NEUMARK et al., 2004). Em outros modelos, a curva de oferta de trabalho pode não ser bem comportada, tendo múltiplos equilíbrios - com o mínimo levando ao equilíbrio socialmente preferível.

Em ambos casos, a institucionalização dos salários mínimos se configura como uma política de regulação do mercado de trabalho com características pré-distributivas, uma vez que altera tanto os incentivos ao trabalho quanto o mark-up dos empregadores antes das trocas de mercado ocorrerem de forma a garantir uma redistribuição eficiente. Diante disso, o relativo consenso formado no debate teórico heterodoxo a partir das críticas institucionalistas e keynesianas reconhece a influência positiva do salário mínimo sobre os salários e nível de emprego. Isso, pois a remuneração ao trabalho é regulada por um piso institucional, influenciada pelo poder de barganha dos trabalhadores e responde politicamente ao estado geral do mercado de trabalho de uma economia. Com efeito, esse consenso ressalta o fato de que o mercado de trabalho e os salários mínimos não são instituições naturais, devendo ser construídas socialmente em uma estrutura socioeconômica específica - reforçando a noção de Polanyi (2000) de trabalho enquanto mercadoria fictícia que deve ser socialmente construída e regulada. Assim, a magnitude dos efeitos do mínimo depende tanto do desenho da política quanto da institucionalidade do mercado de trabalho e da conjuntura econômica na qual a valorização ocorre. 


\section{Mercado de trabalho na China: transformações e institucionalidade}

O mercado de trabalho está entre as instituições mais recentes da China moderna, com pouco mais de 20 anos de existência. Afinal, durante toda a China maoísta (1949-1976), no lugar de um "mercado", havia um "sistema centralizado de alocação de trabalho", caracterizado pela imobilidade dos trabalhadores, alto grau de igualitarismo na definição dos salários e pleno emprego (garantido pelo Estado nas zonas urbanas e pelas comunas agrícolas nas zonas rurais). Não havia mobilidade voluntária nem entre zonas rurais e urbanas e nem entre os empregos urbanos, e o grau de controle sobre a alocação do trabalho era, segundo os estudos comparativos, superior inclusive à União Soviética. Em contrapartida, o Estado administrava os salários, responsabilizava-se por encontrar emprego vitalício e as empresas estatais ofereciam benefícios e bens públicos não comercializáveis aos seus empregados e dependentes. Moradia, serviços médicos, previdência e creche, em conjunto com a promessa de emprego vitalício, compunham a chamada "tigela de ferro de arroz" (铁饭碗, tiě fàn wăn) garantida aos trabalhadores urbanos (KNIGHT, SONG, 2005; NAUGHTON, 2007; MEDEIROS, NOGUEIRA, 2011; NOGUEIRA, 2011).

Quando as reformas começaram, em 1978, mais de dois terços da força de trabalho chinesa de 402 milhões de pessoas estava empregada nas comunas agrícolas, ao passo que os $23 \%$ dos empregados nas zonas urbanas dividiam-se entre as grandes estatais (14\%), as empresas coletivas (5\%) e a administração pública (4\%) - em todos os casos, apenas em empregos públicos (NAUGHTON, 2007). Até as privatizações das empresas estatais, em meados dos anos 90, as transformações no sentido da criação de um mercado de trabalho foram muito graduais. As reformas começam por meio da descentralização da alocação dos trabalhadores, até então monopólio do governo central. Em 1986, os novos trabalhadores estatais passaram a ter que assinar contratos curtos de trabalho, de cinco anos, que poderiam ou não ser renovados. Essa era uma mudança importante em relação à promessa de emprego vitalício, o que significou que a geração mais nova passou a conviver com a possibilidade de desemprego. No início dos anos 90 , casos de demissão entre os mais jovens tornaram-se corriqueiros, bem como a possibilidade de mudança de trabalho. De 
qualquer forma, o desemprego aberto continuava sendo amenizado por políticas ativas, como o controle da migração e a oferta de vagas acima da demanda no setor público.

Depois de anunciar que os jovens trabalhadores teriam contratos curtos de trabalho, a segunda medida foi no sentido de permitir que as empresas estatais fixassem suas remunerações. Até então os salários, definidos centralmente, tinham baixa dispersão, variavam pouco se comparado às economias capitalistas e dependiam da qualificação, posição gerencial, localidade e senioridade. A partir de 1988, salários do setor público passam a ter uma fatia variável, a depender do desempenho da empresa. Em 1992, as empresas públicas ganharam total autonomia para definirem internamente os salários, inclusive as dispersões e diferenciações intrafirma. Junto com o crescimento do setor privado, no qual não havia regulação salarial, essas dispersões salariais passaram a dar forma ao mercado de trabalho chinês (KNIGHT, SONG, 2005; MEDEIROS, NOGUEIRA, 2011; NOGUEIRA, 2011).

Mas o big bang das reformas veio em meados dos anos $90 \mathrm{com}$ as privatizações e, consequente, com as demissões em massa no setor público. Em 1994, a "tigela de ferro" é formalmente quebrada, e todos os trabalhadores são recategorizados em contratos com prazos definidos ou demitidos. Entre empresas estatais (State-Owned Enterprises, SOEs) e empresas coletivas, o número de chineses demitidos entre 1993 e 2004 é impressionante: em torno de 50 milhões de trabalhadores. Nos quatro anos mais intensivos, 1996-1999, a média de demissões foi de 7 milhões de pessoas ao ano. Em 2003, as SOEs tinham reduzido sua fatia no emprego total para $4 \%$, as urbanas coletivas para $1,3 \%$ e as Town-Village Enterprises (TVEs) coletivas para 1,7\%. Em conjunto, o setor público reduziu sua fatia no emprego total de 24\% em 1978 para 7\% no início do novo século (NAUGHTON, 2007).

O principal resultado desse big bang no mercado de trabalho chinês foi o crescimento expressivo do trabalho informal nas regiões urbanas, que chegou a pouco mais da metade do emprego urbano em 2013 (última pesquisa domiciliar detalhada disponível). O governo chinês não dispõe de uma definição própria para o setor informal da economia, portanto diferentes pesquisadores usam cálculos próprios, mas os resultados não são muito díspares. Assumindo uma perspectiva conservadora e considerando trabalho informal apenas aquele que aparece sob a categoria de "outros" e "emprego próprio" segundo definição do Escritório Nacional de Estatísticas, a fatia do 
emprego informal saiu de 17\% em 1990 para 48\% do emprego urbano em 2003 (NBS, vários anos). Em 2013, segundo o CHIP Project, 57\% da força de trabalho urbana estava no setor informal. Desse total, $15 \%$ estavam em "empregos próprios" (donos de negócios próprios sem registro para efeitos de tributação e seguridade social) e $42 \%$ eram trabalhadores casuais, de baixa escolaridade e precarizados (LIANG, APPLETON, SONG, 2016).

Os "casuais" são trabalhadores captados pelo censo populacional e que não estão envolvidos em nenhuma forma registrada de trabalho. Formalmente, para as secretarias de trabalho das cidades em que trabalham, eles não existem e efetivamente constituem uma massa de trabalhadores em situação de maior vulnerabilidade socioeconômica. São os pequenos negócios precários e sem registro voltados para comércio e serviços que hoje povoam as pequenas e grandes cidades chinesas. Nas grandes cidades, eles são os numerosos ambulantes de calçadas, vendedores de alimentos nas ruas, donos das barraquinhas que consertam roupas e bicicletas, babás e trabalhadores domésticos, e aqueles que transformam suas residências em pequenas lojas de comida, roupas e utensílios. A maior parte é composta de migrantes vindos das zonas rurais e sem registro de moradia.

Os migrantes sem registro são uma população estimada em 260 milhões em 2013 (LIANG, APPLETON, SONG, 2016). Eles começaram a se tornar numerosos nas cidades chinesas a partir de meados dos anos $80 \mathrm{com}$ a flexibilização do registro de moradia, (hùkǒu), um mecanismo de controle migratório interno que dá ao Estado a capacidade de direcionar a velocidade da urbanização, os limites populacionais das grandes cidades e a oferta de mão-de-obra. Com a flexibilização, deu-se início não apenas a migração das zonas rurais para as pequenas cidades povoadas com empresas coletivas, mas a migração de longa distância, para as recém-abertas fábricas da costa, para os canteiros de obra nas cidades, e, em um segundo momento, para tocar os pequenos negócios próprios no mercado informal. Conseguir hùkǒu nas grandes cidades (especialmente nas costeiras) continua sendo muito mais difícil do que nas médias e pequenas cidades, onde atualmente a concessão é quase automática uma evidente tentativa do governo de promover uma urbanização mais descentralizada (WAN, 2008; SICULAR et al. 2007). 
A mais relevante dispersão do mercado de trabalho chinês é justamente dos migrantes sem registro e do setor informal. Os migrantes sem hùkǒu representavam 46\% da força de trabalho urbana em 2005 (125 milhões de pessoas), 53\% em 2010 (169 milhões) e a estimativa é de que chegariam a 68\% em 2020 (292 milhões) (KNIGHT, DENG, LI, 2010). Ao se observar exclusivamente os setores de manufatura e construção civil, eles são maioria, ocupando, respectivamente, $70 \%$ e $80 \%$ dos postos. Sua remuneração média é geralmente metade daquela conseguida, na média, por um trabalhador com registro urbano. Isso os posiciona na base da pirâmide de remunerações do trabalho nas zonas urbanas. Conforme resume Medeiros (2013), formou-se um grande dualismo entre dois principais segmentos do mercado de trabalho: o dos assalariados com domicílio urbano e os migrantes sem registro.

Em resumo, desde o final da década de 90, o mercado de trabalho chinês ficou cada vez mais parecido com a tipificação dos países em desenvolvimento populosos: grande fatia de emprego informal, sua maioria de baixa produtividade, baixos salários e com rede precária de proteção social, de um lado, convivendo com as ilhas capitalistas de produtividade e salários mais elevados, de outro. A precarização, no caso chinês, é fortemente marcada pelo trabalhador migrante sem registro (DU, PAN, 2009).

Não por acaso, na virada do século, os conflitos sociais eram intensos na China. Os chineses enfrentavam não apenas o aumento da desigualdade de renda e a concentração de capital (NOGUEIRA, GUIMARÃES, BRAGA, 2019) como também se depararam com uma violenta redução dos seus programas de proteção social na saúde e educação com o fim da "tigela de ferro" e com a ausência completa de proteção social para trabalhadores sem hùkǒu (NOGUEIRA, BACIL, GUIMARÃES, 2020). Isso levou à piora em indicadores fundamentais de bem-estar e a numerosos casos de famílias que foram à falência por gastos com saúde e serviços de educação, o que aumentou a insatisfação popular medida pelos chamados "incidentes de massa", cujos casos saltaram de 10 mil para 87 mil entre 1994 e 2005 segundo dados oficiais. Foi com o objetivo declarado de evitar caos social que a gestão Hu Jintao e Wen Jiabao (20032013) lançou um conjunto de políticas de combate às desigualdades sob o slogan de construção de uma "sociedade harmoniosa". Dentre as várias medidas, estavam as intervenções diretas no mercado de trabalho para garantir aumentos consistentes dos salários, que vamos discutir na seção seguinte. 


\section{Acumulação, bem-estar e salário mínimo}

A "sociedade harmoniosa" foi uma estratégia de desenvolvimento abrangente, que buscava fazer convergir a proteção social, a mediação de conflitos capital-trabalho, e a tentativa de mudança do padrão de acumulação via um conjunto variado de políticas públicas. Essas políticas incluíam: (i) a criação de sistemas nacionais de seguridade social e serviços públicos essenciais gratuitos (no caso da educação básica) ou com contribuições compartilhadas, como no caso da saúde e previdência; (ii) os programas de desenvolvimento regional para as zonas mais pobres, notadamente oeste, nordeste e centro; e (iii) as intervenções no mercado de trabalho para garantir aumentos consistentes dos salários (NOGUEIRA, 2015, faz uma discussão detalhada destas políticas). De explícita inspiração confucionista, o slogan da "sociedade harmoniosa" faz referência à necessidade de mediação de conflitos pelo Estado como forma de mitigar as instabilidades sociais e garantir a continuidade do desenvolvimento do país.

Nesse contexto, do ponto de vista específico do mercado de trabalho, uma política adquiriu relevância central na determinação dos salários e na mediação dos conflitos durante a era da sociedade harmoniosa: a institucionalização de uma política ativa de salários mínimos regionais. Com seu sistema político descentralizado de dimensões continentais e elevada heterogeneidade entre províncias, a China adotou um regime de fixação de pisos para a remuneração ao trabalho a nível provincial, levando em consideração diferenças de custos de vida e desenvolvimento de cada província e condado.

O salário mínimo foi formalmente implementado em 2004, após a promulgação das "Provisões do Salário Mínimo pelo Ministério de Recursos Humanos e Seguridade Social" (SECURITY, 2004). Essas provisões estabelecem que o piso dos salários é válido para todas as empresas, explicitando mecanismos de aplicação da lei, sanções em caso de descumprimento e ajuste pelo menos a cada dois anos. Desde então, planos de ajuste dos mínimos feitos a nível provincial considerando os custos de vida, emprego e pobreza urbana são negociados com associações sindicais, sendo depois encaminhados para discussão pelos oficiais de comitês provinciais e, finalmente, submetidos a aprovação pelo governo central. 
É importante ressaltar que a valorização dos salários mínimos na China apresenta grandes diferenças em relação ao caso brasileiro. Trata-se de uma política impulsionada pelo governo central e gerida pelos governos locais - admitindo elevada variação entre províncias. Dentro da mesma província também se observa variação nos seus níveis (XING, XU, 2016). Outra diferença importante é a existência de salários mínimos horários, tendo em vista a heterogênea quantidade de dias e horas trabalhados como consequência da indissociabilidade entre informalidade e formalidade no mercado de trabalho chinês. No entanto, por conta dos salários horários, o efeito distributivo dos mínimos no mercado informal seria potencialmente análogo ao "efeito farol" no caso brasileiro, sinalizando aumentos na remuneração dos trabalhadores que estão à margem da formalidade (no caso da China, aqueles sem hùkǒu).

Do ponto de vista do padrão de desenvolvimento, a política de regulação do mercado de trabalho e de aumentos substantivos do salário mínimo são coerentes com o objetivo de alterar o padrão de acumulação na China e torná-lo menos dependente das exportações e dos investimentos e direcioná-lo para o consumo interno e para as inovações, sobretudo via a consolidação de empresas chinesas na liderança das cadeias globais de valor. Afinal, para tal guinada no padrão de acumulação, são necessários uma massa salarial crescente e um estado de bem-estar que dê segurança mínima para que a população consuma mais.

Sob a atual gestão de Xi Jinping e Li Keqiang, o slogan da estratégia de desenvolvimento mudou para a construção de uma "sociedade moderadamente próspera", conforme se vê no $13^{\circ}$ Plano Quinquenal (2016-2020). Ou, de maneira muito mais abrangente, para o estabelecimento do "sonho chinês", que descreve o conjunto de ideais individuais e nacionais para a construção de uma China grandiosa. A mudança do padrão de acumulação ganhou muito mais urgência sobretudo frente ao acirramento das disputas estratégicas com os Estados Unidos. O principal objetivo do $13^{\circ}$ Plano é mudar de um crescimento puxado pelos investimentos e pelas exportações para um crescimento puxado pela inovação e pela demanda doméstica a fim de aumentar a produtividade total dos fatores e liberar o potencial de consumo interno. A política industrial que materializa esse objetivo está resumida no plano estratégico "Made in China 2025", lançado em 2015, que elenca um conjunto de setores e políticas de apoio para que empresas chinesas assumam a liderança em segmentos 
tecnologicamente avançados, de inteligência artificial e biotecnologia à automação industrial, semicondutores e indústria aeroespacial (AGLIETTA, BAI, 2016).

$\mathrm{Na}$ atual gestão de Xi Jinping, ou na era do "sonho chinês", nota-se uma ênfase muito maior no upgrade tecnológico do que na contenção dos desequilíbrios domésticos. Em parte, isso reflete o estabelecimento prévio de um estado de bem-estar social mínimo e de cunho produtivista que alivia o conflito social (NOGUEIRA, BACIL, GUIMARÃES, 2020). No entanto, não há dúvidas de que a disputa estratégica com os Estados Unidos se impõe como o principal desafio para a continuidade do "sonho chinês" e para a própria continuidade da China enquanto potência. Isso transforma a disputa global pela liderança tecnológica no primeiro objetivo nacional. Os resultados do ponto de vista distributivo, no entanto, já são visíveis, e a distribuição da renda, que vinha melhorando desde a crise financeira de 2008, estacionou entre 2015-2018 (NOGUEIRA, GUIMARÃES, BRAGA, 2019). Do ponto de vista da política de salário mínimo, também há uma inflexão importante desde que Xi Jinping assumiu o poder, conforme vamos demonstrar na seção seguinte, na qual nos dedicamos a observar de maneira empírica a evolução do salário mínimo, sua relação com o salário médio e sua variação regional.

\section{Evolução do salário mínimo nacional na China entre 2004-2018}

Mas afinal, como tem evoluído o salário mínimo na China desde o estabelecimento da "sociedade harmoniosa" e durante o atual "sonho chinês" de Xi Jinping? Esse artigo contribui para o debate ao desenvolver um cálculo próprio do salário mínimo nacional. Como já discutimos, a elevada heterogeneidade no desenvolvimento socioeconômico do país está por trás da relativa complexidade da política de salários mínimos na China, uma vez que eles são determinados provincialmente e isso inviabiliza um cálculo direto de mínimo nacional. É, portanto, necessário estimar um indicador de mínimo nacional que leve em consideração a força de trabalho provincial e o valor do salário mínimo provincial. Para tal, duas fontes foram utilizadas: a base do National Bureau of Statistics (NBS, 2020) e os dados de salário mínimo mensal provincial na base das consultorias China Briefing e CEIC Data (CEIC, 2018; CHINA BRIEFING, 2016) - cujas fontes primárias são o Ministério de Recursos Humanos. 
Assim, montamos uma base de dados em painel cobrindo os valores nominais do salário mínimo provincial ao longo dos anos de 2004 a 2018, além dos respectivos valores de salários médios e da força de trabalho obtidos junto ao NBS. Para agregar os dados provinciais para valores regionais e construir um indicador de salário mínimo nacional, adotamos a metodologia empregada por Xing e Xu (2016). O mínimo nacional (SMN) no tempo t é dado por uma média do mínimo na província j ponderada pela sua força de trabalho - como indicado na equação (1). Por último, levando em consideração os diferenciais de custo de vida, utilizamos o deflator desenvolvido por Brandt e Holtz (2006) para chegar aos valores de Mínimo Real em valores de RMB 2004 indicados na tabela II. O mesmo procedimento é feito com os salários médios para chegar aos valores reais agregados por região e, então, calcular o indicador de salário mínimo relativo ao médio na equação (2). As variações reais observadas entre 2004-2018 nas variáveis de salário mínimo, médio e mínimo relativo ao médio são exibidas na tabela I. Além das tabelas, gráficos de evolução dos mínimos são detalhados na sequência.

SMN $t=\frac{\sum \text { SMjt* } * \text { emprego } j t}{\sum \text { emprego } t}(1) \quad ; \quad S M R m t=\frac{\sum S M j t}{\sum S M e d j t}$

Os resultados exibidos no gráfico I apontam para uma expressiva valorização de 255\% dos salários mínimos reais (já descontada a inflação) na China ao longo do período de 2004-2018. Pelos nossos cálculos, o salário mínimo nacional na China começa em um nível baixo, de \$ 350 yuans em 2004, até atingir \$ 1240 yuans em 2018 - equivalendo, portanto, a $R \$ 90$ em 2004 e a $R \$ 930$ em 2018. Apesar de parecer equivalente ao nível do salário mínimo brasileiro em 2018, o poder de compra doméstico da moeda chinesa é muito maior, o que sugere um nível de bem-estar igualmente superior para o trabalhador chinês frente ao brasileiro. Esse expressivo crescimento real do salário mínimo chinês pode estar ligado tanto a uma alta generalizada dos salários (em consequência de um mercado de trabalho aquecido e aumento do poder de barganha dos trabalhadores) quanto a uma dimensão ativa de uma política de intervenção no mercado de trabalho e voltada para a valorização dos salários mais baixos, via aumento do salário mínimo. 
Gráfico I - Evolução dos salários mínimos reais entre 2004-2018 (RMB 2004)

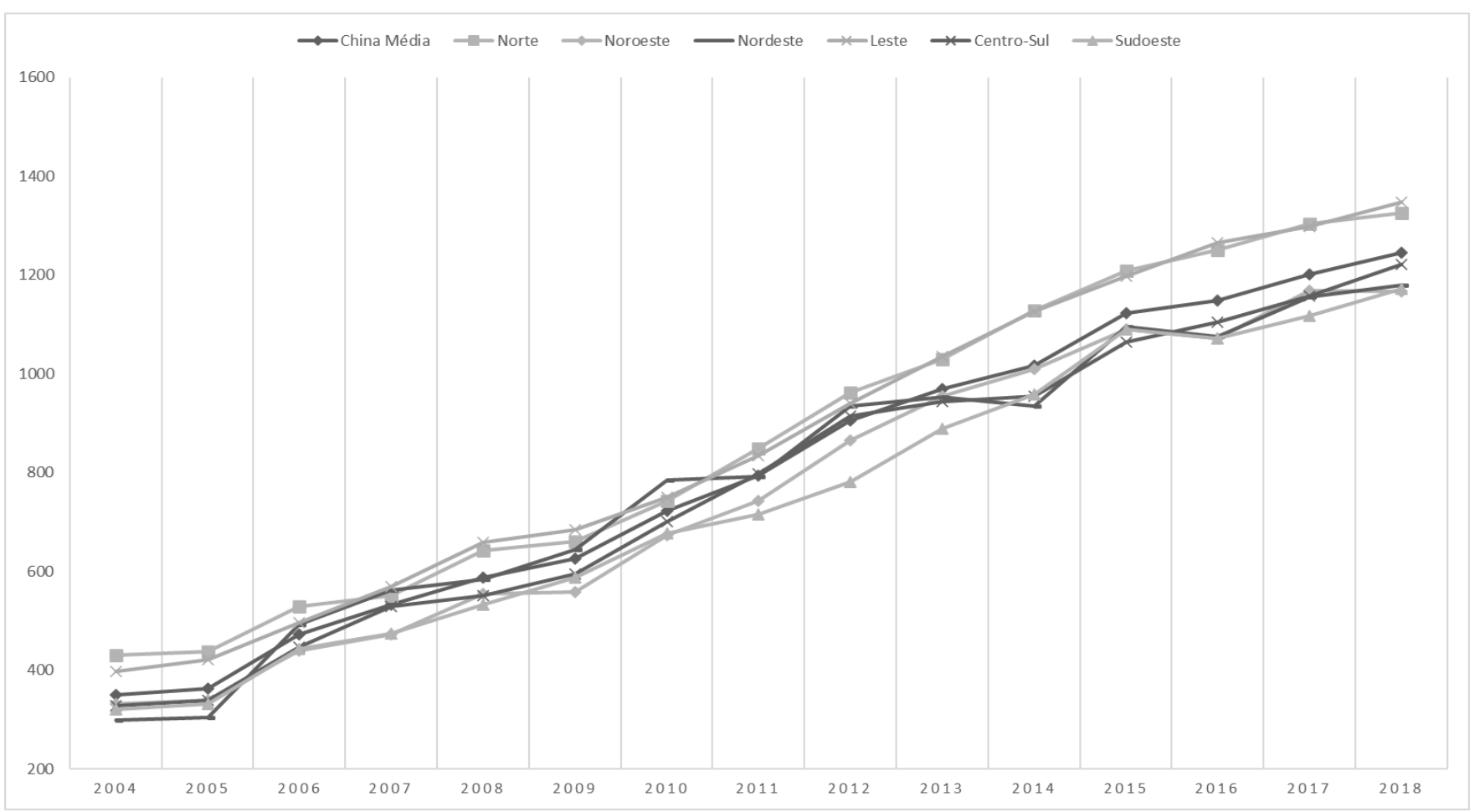

Fonte: Elaboração própria a partir de CEIC data

Mas mesmo com uma alta tão expressiva do salário mínimo no período, o salário médio da China cresceu ainda mais rápido. Entre 2004 e 2018, o salário mínimo relativo (salário mínimo em relação ao salário médio) caiu $6 \%$. Isso porque ainda que o salário mínimo real tenha crescido expressivos $255 \%$, o médio real cresceu ainda mais rápido, com variação de 277\% entre 2004-2018 (Tabela I). Nossos dados indicam que o salário mínimo cresceu em ritmo equivalente ou mais alto em relação ao salário médio durante boa parte da era da "sociedade harmoniosa" (que vai da posse de Hu Jintao, em 2003, até sua saída, em 2013). Entre 2004 e 2009, salário mínimo e salário médio cresceram em ritmos muito parecidos, e, portanto, o salário mínimo relativo mostrou variação negativa de apenas 1\%. Entre 2009 e 2014, já como uma política ativa de reação à crise financeira global do ano anterior, o salário mínimo relativo cresceu $9 \%$, o que sugere uma intervenção maior do governo para puxar os salários para cima por meio de um aumento do mínimo maior do que o médio. Na era sob liderança de Xi Jinping, de 2014 a 2018, o salário mínimo passou a crescer de maneira bem mais lenta do que o salário médio. Com isso, entre 2014 e 2018, o salário mínimo relativo caiu 13\%, o que 
sugere um papel menor do salário mínimo como política de valorização dos salários (Tabela I).

Tabela I - Variações dos salários mínimo, médio e mínimo relativo entre 20042018

\begin{tabular}{|c|c|c|c|c|c|c|c|c|c|c|c|c|}
\hline \multirow{2}{*}{ Variação (\%) } & \multicolumn{4}{|c|}{ Salário Mínimo Real } & \multicolumn{4}{|c|}{ Salário Médio Real } & \multicolumn{4}{|c|}{ Salário Mínimo Relativo } \\
\hline & 2004-09 & 2009-14 & 2014-18 & 2004-18 & 2004-09 & $2009-14$ & 2014-18 & 2004-18 & 2004-09 & 2009-14 & 2014-18 & 2004-18 \\
\hline China Média & $79 \%$ & $62 \%$ & $23 \%$ & $255 \%$ & $81 \%$ & $49 \%$ & $40 \%$ & $277 \%$ & $-1 \%$ & $9 \%$ & $-13 \%$ & $-6 \%$ \\
\hline Norte & $53 \%$ & $71 \%$ & $17 \%$ & $208 \%$ & $91 \%$ & $44 \%$ & $34 \%$ & $269 \%$ & $-20 \%$ & $19 \%$ & $-13 \%$ & $-17 \%$ \\
\hline Beijing & $41 \%$ & $49 \%$ & $40 \%$ & $194 \%$ & $81 \%$ & $52 \%$ & $34 \%$ & $268 \%$ & $-22 \%$ & $-2 \%$ & $4 \%$ & $-20 \%$ \\
\hline Tianjin & $57 \%$ & $76 \%$ & $15 \%$ & $217 \%$ & $78 \%$ & $41 \%$ & $33 \%$ & $233 \%$ & $-12 \%$ & $25 \%$ & $-13 \%$ & $-5 \%$ \\
\hline Hebei & $64 \%$ & $69 \%$ & $13 \%$ & $214 \%$ & $92 \%$ & $40 \%$ & $48 \%$ & $298 \%$ & $-15 \%$ & $21 \%$ & $-24 \%$ & $-21 \%$ \\
\hline Shanxi & $54 \%$ & $73 \%$ & $10 \%$ & $194 \%$ & $88 \%$ & $51 \%$ & $27 \%$ & $261 \%$ & $-18 \%$ & $15 \%$ & $-13 \%$ & $-19 \%$ \\
\hline Inner Mongolia & $56 \%$ & $89 \%$ & $10 \%$ & $225 \%$ & $101 \%$ & $52 \%$ & $31 \%$ & $299 \%$ & $-22 \%$ & $24 \%$ & $-15 \%$ & $-18 \%$ \\
\hline Nordeste & $116 \%$ & $45 \%$ & $26 \%$ & $295 \%$ & $83 \%$ & $46 \%$ & $34 \%$ & $260 \%$ & $18 \%$ & $-1 \%$ & $-6 \%$ & $10 \%$ \\
\hline Liaoning & $148 \%$ & $24 \%$ & $17 \%$ & $260 \%$ & $81 \%$ & $35 \%$ & $32 \%$ & $225 \%$ & $37 \%$ & $-9 \%$ & $-11 \%$ & $11 \%$ \\
\hline Jilin & $89 \%$ & $74 \%$ & $27 \%$ & $317 \%$ & $84 \%$ & $56 \%$ & $39 \%$ & $297 \%$ & $3 \%$ & $12 \%$ & $-9 \%$ & $5 \%$ \\
\hline Heilongjiang & $109 \%$ & $45 \%$ & $35 \%$ & $310 \%$ & $82 \%$ & $48 \%$ & $32 \%$ & $256 \%$ & $15 \%$ & $-2 \%$ & $2 \%$ & $15 \%$ \\
\hline Leste & $72 \%$ & $65 \%$ & $20 \%$ & $238 \%$ & $79 \%$ & $49 \%$ & $35 \%$ & $260 \%$ & $-4 \%$ & $10 \%$ & $-11 \%$ & $-6 \%$ \\
\hline Shanghai & $35 \%$ & $63 \%$ & $25 \%$ & $174 \%$ & $84 \%$ & $36 \%$ & $34 \%$ & $234 \%$ & $-27 \%$ & $20 \%$ & $-6 \%$ & $-18 \%$ \\
\hline Jiangsu & $72 \%$ & $65 \%$ & $17 \%$ & $230 \%$ & $72 \%$ & $48 \%$ & $32 \%$ & $234 \%$ & $0 \%$ & $11 \%$ & $-12 \%$ & $-1 \%$ \\
\hline Zhejiang & $88 \%$ & $47 \%$ & $15 \%$ & $217 \%$ & $38 \%$ & $43 \%$ & $37 \%$ & $172 \%$ & $36 \%$ & $3 \%$ & $-16 \%$ & $17 \%$ \\
\hline Anhui & $64 \%$ & $92 \%$ & $14 \%$ & $258 \%$ & $112 \%$ & $51 \%$ & $36 \%$ & $335 \%$ & $-23 \%$ & $27 \%$ & $-17 \%$ & $-18 \%$ \\
\hline Fujian & $123 \%$ & $50 \%$ & $19 \%$ & $299 \%$ & $69 \%$ & $62 \%$ & $30 \%$ & $256 \%$ & $32 \%$ & $-7 \%$ & $-8 \%$ & $12 \%$ \\
\hline Jiangxi & $80 \%$ & $82 \%$ & $29 \%$ & $322 \%$ & $81 \%$ & $64 \%$ & $41 \%$ & $319 \%$ & $-1 \%$ & $11 \%$ & $-9 \%$ & $1 \%$ \\
\hline Shandong & $70 \%$ & $69 \%$ & $20 \%$ & $244 \%$ & $80 \%$ & $52 \%$ & $35 \%$ & $268 \%$ & $-6 \%$ & $12 \%$ & $-11 \%$ & $-7 \%$ \\
\hline Centro-Sul & $81 \%$ & $60 \%$ & $28 \%$ & $272 \%$ & $77 \%$ & $51 \%$ & $43 \%$ & $282 \%$ & $2 \%$ & $6 \%$ & $-10 \%$ & $-3 \%$ \\
\hline Henan & $67 \%$ & $85 \%$ & $37 \%$ & $324 \%$ & $97 \%$ & $34 \%$ & $42 \%$ & $272 \%$ & $-15 \%$ & $39 \%$ & $-3 \%$ & $14 \%$ \\
\hline Hubei & $60 \%$ & $74 \%$ & $41 \%$ & $293 \%$ & $99 \%$ & $60 \%$ & $41 \%$ & $351 \%$ & $-20 \%$ & $9 \%$ & $0 \%$ & $-13 \%$ \\
\hline Hunan & $65 \%$ & $63 \%$ & $18 \%$ & $217 \%$ & $70 \%$ & $53 \%$ & $42 \%$ & $270 \%$ & $-3 \%$ & $7 \%$ & $-17 \%$ & $-14 \%$ \\
\hline Guangdong & $98 \%$ & $54 \%$ & $25 \%$ & $282 \%$ & $52 \%$ & $40 \%$ & $39 \%$ & $196 \%$ & $31 \%$ & $10 \%$ & $-10 \%$ & $29 \%$ \\
\hline Guangxi & $144 \%$ & $46 \%$ & $11 \%$ & $295 \%$ & $92 \%$ & $41 \%$ & $45 \%$ & $294 \%$ & $27 \%$ & $3 \%$ & $-24 \%$ & $0 \%$ \\
\hline Hainan & $57 \%$ & $53 \%$ & $42 \%$ & $242 \%$ & $72 \%$ & $74 \%$ & $47 \%$ & $341 \%$ & $-9 \%$ & $-12 \%$ & $-3 \%$ & $-22 \%$ \\
\hline Sudoeste & $83 \%$ & $63 \%$ & $22 \%$ & $266 \%$ & $76 \%$ & $48 \%$ & $56 \%$ & $306 \%$ & $4 \%$ & $10 \%$ & $-21 \%$ & $-10 \%$ \\
\hline Chongqing & $55 \%$ & $52 \%$ & $32 \%$ & $212 \%$ & $99 \%$ & $57 \%$ & $33 \%$ & $315 \%$ & $-22 \%$ & $-3 \%$ & $-1 \%$ & $-25 \%$ \\
\hline Sichuan & $74 \%$ & $85 \%$ & $20 \%$ & $285 \%$ & $75 \%$ & $61 \%$ & $41 \%$ & $299 \%$ & $-1 \%$ & $15 \%$ & $-15 \%$ & $-3 \%$ \\
\hline Guizhou & $100 \%$ & $64 \%$ & $24 \%$ & $308 \%$ & $110 \%$ & $65 \%$ & $40 \%$ & $384 \%$ & $-5 \%$ & $-1 \%$ & $-11 \%$ & $-16 \%$ \\
\hline Yunnan & $83 \%$ & $73 \%$ & $10 \%$ & $249 \%$ & $65 \%$ & $47 \%$ & $57 \%$ & $282 \%$ & $11 \%$ & $18 \%$ & $-30 \%$ & $-9 \%$ \\
\hline Tibet & $110 \%$ & $41 \%$ & $30 \%$ & $283 \%$ & $36 \%$ & $20 \%$ & $66 \%$ & $171 \%$ & $54 \%$ & $18 \%$ & $-22 \%$ & $42 \%$ \\
\hline Noroeste & $68 \%$ & $81 \%$ & $16 \%$ & $252 \%$ & $84 \%$ & $51 \%$ & $37 \%$ & $281 \%$ & $-8 \%$ & $20 \%$ & $-16 \%$ & $-8 \%$ \\
\hline Shaanxi & $31 \%$ & $83 \%$ & $24 \%$ & $195 \%$ & $102 \%$ & $48 \%$ & $35 \%$ & $305 \%$ & $-35 \%$ & $24 \%$ & $-9 \%$ & $-27 \%$ \\
\hline Gansu & $71 \%$ & $86 \%$ & $11 \%$ & $252 \%$ & $84 \%$ & $52 \%$ & $41 \%$ & $294 \%$ & $-7 \%$ & $22 \%$ & $-21 \%$ & $-11 \%$ \\
\hline Qinghai & $58 \%$ & $82 \%$ & $11 \%$ & $219 \%$ & $70 \%$ & $48 \%$ & $42 \%$ & $254 \%$ & $-7 \%$ & $23 \%$ & $-21 \%$ & $-10 \%$ \\
\hline Ningxia & $52 \%$ & $99 \%$ & $20 \%$ & $265 \%$ & $103 \%$ & $43 \%$ & $36 \%$ & $294 \%$ & $-25 \%$ & $39 \%$ & $-11 \%$ & $-7 \%$ \\
\hline Xinjiang & $151 \%$ & $61 \%$ & $13 \%$ & $356 \%$ & $65 \%$ & $66 \%$ & $33 \%$ & $265 \%$ & $52 \%$ & $-3 \%$ & $-15 \%$ & $25 \%$ \\
\hline
\end{tabular}

Fonte: Elaboração própria a partir de CEIC data

A função mais importante da política de salário mínimo no período parece ter sido reequilibrar a distribuição de renda nacional. Nosso resultado mais importante aponta para uma valorização mais acentuada do salário mínimo nas regiões mais pobres em comparação às mais ricas, uma tentativa de reduzir a heterogeneidade regional das remunerações. De acordo com o Mapa I, a região leste (costeira), a mais desenvolvida e industrializada, registrou valorização real abaixo da média, de $238 \%$ 
entre 2004 e 2018. Liderando os aumentos do salário mínimo, destacam-se as regiões nordeste (295\%), centro-sul $(272 \%)$, sudoeste $(266 \%)$ e noroeste $(252 \%)$. Essa evolução heterogênea confirma um catching-up dos salários mínimos nas regiões menos desenvolvidas.

Tabela II - Valores mensais do salário mínimo real entre 2004-2018

\begin{tabular}{|c|c|c|c|c|c|c|c|c|c|c|c|c|c|c|c|}
\hline & \multicolumn{15}{|c|}{ Salário Mínimo Real (mensal em valores de 2004) } \\
\hline & 2004 & 2005 & 2006 & 2007 & 2008 & 2009 & 2010 & 2011 & 2012 & 2013 & 2014 & 2015 & 2016 & 2017 & 2018 \\
\hline China Média & 351 & 363 & 473 & 533 & 588 & 626 & 723 & 795 & 906 & 969 & 1017 & 1123 & 1148 & 1202 & 1246 \\
\hline Norte & 431 & 439 & 528 & 551 & 643 & 661 & 743 & 848 & 963 & 1029 & 1129 & 1209 & 1252 & 1303 & 1326 \\
\hline Beijing & 525 & 542 & 567 & 592 & 654 & 738 & 713 & 816 & 960 & 1011 & 1102 & 1208 & 1304 & 1404 & 1544 \\
\hline Tianjin & 450 & 445 & 642 & 613 & 697 & 706 & 770 & 924 & 1016 & 1135 & 1241 & 1343 & 1396 & 1454 & 1428 \\
\hline Hebei & 400 & 393 & 493 & 535 & 652 & 656 & 764 & 888 & 1040 & 1009 & 1112 & 1105 & 1219 & 1205 & 1256 \\
\hline Shanxi & 400 & 438 & 471 & 499 & 622 & 617 & 706 & 773 & 866 & 965 & 1068 & 1176 & 1154 & 1194 & 1174 \\
\hline Inner Mongolia & 380 & 375 & 471 & 518 & 588 & 592 & 759 & 841 & 937 & 1026 & 1120 & 1209 & 1187 & 1262 & 1237 \\
\hline Nordeste & 299 & 305 & 493 & 562 & 583 & 645 & 785 & 792 & 935 & 953 & 935 & 1096 & 1075 & 1155 & 1179 \\
\hline Liaoning & 316 & 345 & 573 & 647 & 605 & 783 & 928 & 881 & 1015 & 988 & 971 & 1128 & 1108 & 1161 & 1138 \\
\hline Jilin & 300 & 296 & 447 & 471 & 562 & 566 & 691 & 801 & 898 & 1003 & 985 & 1091 & 1071 & 1276 & 1251 \\
\hline Heilongjiang & 280 & 274 & 460 & 569 & 583 & 586 & 737 & 697 & 893 & 868 & 851 & 1070 & 1047 & 1032 & 1149 \\
\hline Leste & 399 & 422 & 496 & 569 & 660 & 685 & 750 & 834 & 941 & 1035 & 1127 & 1198 & 1266 & 1299 & 1348 \\
\hline Shanghai & 620 & 641 & 718 & 758 & 821 & 835 & 944 & 1025 & 1132 & 1231 & 1359 & 1489 & 1585 & 1649 & 1701 \\
\hline Jiangsu & 430 & 444 & 612 & 693 & 735 & 740 & 810 & 913 & 1030 & 1125 & 1217 & 1201 & 1281 & 1355 & 1419 \\
\hline Zhejiang & 445 & 483 & 626 & 693 & 830 & 835 & 928 & 1049 & 1022 & 1117 & 1232 & 1371 & 1347 & 1441 & 1412 \\
\hline Anhui & 315 & 325 & 378 & 423 & 472 & 517 & 499 & 612 & 835 & 810 & 992 & 975 & 1153 & 1129 & 1129 \\
\hline Fujian & 310 & 315 & 313 & 515 & 590 & 692 & 668 & 765 & 910 & 963 & 1039 & 1022 & 1137 & 1114 & 1238 \\
\hline Jiangxi & 280 & 310 & 349 & 333 & 501 & 505 & 607 & 577 & 679 & 935 & 918 & 1128 & 1108 & 1097 & 1181 \\
\hline Shandong & 390 & 434 & 476 & 564 & 657 & 661 & 776 & 881 & 968 & 1049 & 1120 & 1179 & 1238 & 1297 & 1342 \\
\hline Centro-Sul & 328 & 339 & 446 & 530 & 550 & 596 & 701 & 797 & 915 & 944 & 955 & 1065 & 1106 & 1159 & 1222 \\
\hline Henan & 265 & 276 & 335 & 343 & 412 & 443 & 557 & 641 & 843 & 821 & 821 & 914 & 1014 & 1147 & 1124 \\
\hline Hubei & 295 & 315 & 321 & 372 & 392 & 471 & 590 & 721 & 859 & 836 & 821 & 973 & 1071 & 1183 & 1159 \\
\hline Hunan & 350 & 345 & 461 & 555 & 575 & 579 & 717 & 817 & 905 & 961 & 944 & 1024 & 1006 & 1133 & 1110 \\
\hline Guangdong & 400 & 439 & 590 & 744 & 781 & 793 & 918 & 1104 & 1075 & 1244 & 1220 & 1467 & 1437 & 1407 & 1529 \\
\hline Guangxi & 310 & 315 & 489 & 639 & 608 & 756 & 731 & 850 & 993 & 963 & 1102 & 1084 & 1062 & 1040 & 1223 \\
\hline Hainan & 350 & 344 & 483 & 535 & 547 & 551 & 705 & 670 & 827 & 856 & 841 & 948 & 1056 & 1045 & 1199 \\
\hline Sudoeste & 321 & 332 & 443 & 475 & 532 & 588 & 677 & 716 & 782 & 889 & 958 & 1091 & 1072 & 1118 & 1172 \\
\hline Chongqing & 350 & 360 & 401 & 453 & 504 & 544 & 606 & 578 & 720 & 842 & 827 & 968 & 948 & 1114 & 1092 \\
\hline Sichuan & 322 & 346 & 472 & 531 & 553 & 560 & 711 & 677 & 814 & 908 & 1034 & 1089 & 1074 & 1064 & 1240 \\
\hline Guizhou & 300 & 296 & 489 & 525 & 590 & 600 & 740 & 790 & 769 & 826 & 984 & 1239 & 1213 & 1248 & 1223 \\
\hline Yunnan & 331 & 362 & 465 & 500 & 596 & 606 & 717 & 775 & 864 & 956 & 1051 & 1146 & 1125 & 1179 & 1155 \\
\hline Tibet & 300 & 297 & 389 & 366 & 421 & 629 & 611 & 757 & 737 & 908 & 887 & 1016 & 1002 & 993 & 1150 \\
\hline Noroeste & 332 & 340 & 439 & 473 & 555 & 559 & 673 & 744 & 865 & 955 & 1009 & 1091 & 1071 & 1168 & 1167 \\
\hline Shaanxi & 400 & 394 & 466 & 499 & 519 & 522 & 641 & 689 & 781 & 874 & 956 & 1091 & 1071 & 1204 & 1181 \\
\hline Gansu & 335 & 370 & 366 & 410 & 563 & 572 & 677 & 646 & 811 & 963 & 1063 & 1138 & 1115 & 1203 & 1180 \\
\hline Qinghai & 330 & 325 & 437 & 425 & 519 & 522 & 649 & 737 & 835 & 813 & 948 & 936 & 919 & 1075 & 1054 \\
\hline Ningxia & 320 & 315 & 403 & 416 & 484 & 487 & 599 & 721 & 859 & 988 & 971 & 1091 & 1071 & 1190 & 1167 \\
\hline Xinjiang & 275 & 296 & 523 & 613 & 692 & 689 & 798 & 919 & 1033 & 1137 & 1110 & 1197 & 1179 & 1169 & 1254 \\
\hline
\end{tabular}

Fonte: Elaboração própria a partir de CEIC data

Mais do que isso, a comparação entre o período da "sociedade harmoniosa" e o período do "sonho chinês" nos leva a concluir que o salário mínimo foi um instrumento de redução das desigualdades regionais apenas no primeiro período. É o que sugere a comparação entre os Mapas II e III. Entre 2004 e 2014, ou seja, durante o período da 
"sociedade harmoniosa", o salário mínimo frente ao salário médio (mínimo relativo) cresceu mais rápido nas províncias mais pobres das regiões nordeste (17\%), sudoeste (15\%) e noroeste (10\%). A região leste, mais rica e industrializada, teve crescimento no mínimo relativo de apenas 6\% entre 2004 e 2014, o segundo mais baixo (Mapa II).

Já durante os anos iniciais do "sonho chinês" (2014-2018), o uso do salário mínimo como instrumento para redução das desigualdades regionais desaparece. $\mathrm{Na}$ verdade, o salário mínimo relativo foi negativo em todas as províncias, o que demonstra que o salário mínimo estava crescendo mais lentamente do que o salário médio. Entre 2014 e 2018, nas regiões mais pobres, notadamente regiões sudoeste e noroeste, o salário relativo despencou $-21 \%$ e $-16 \%$, respectivamente (Mapa III). No entanto, também na região mais rica, leste, o mínimo relativo tem variação negativa no período, de expressivos $-11 \%$. Isso sugere que o salário mínimo perde, de maneira generalizada, seu papel na política nacional de elevação de salários e melhora nas condições de vida dos mais vulneráveis.

Mapa I - Salários mínimos reais por região (2004-2018)

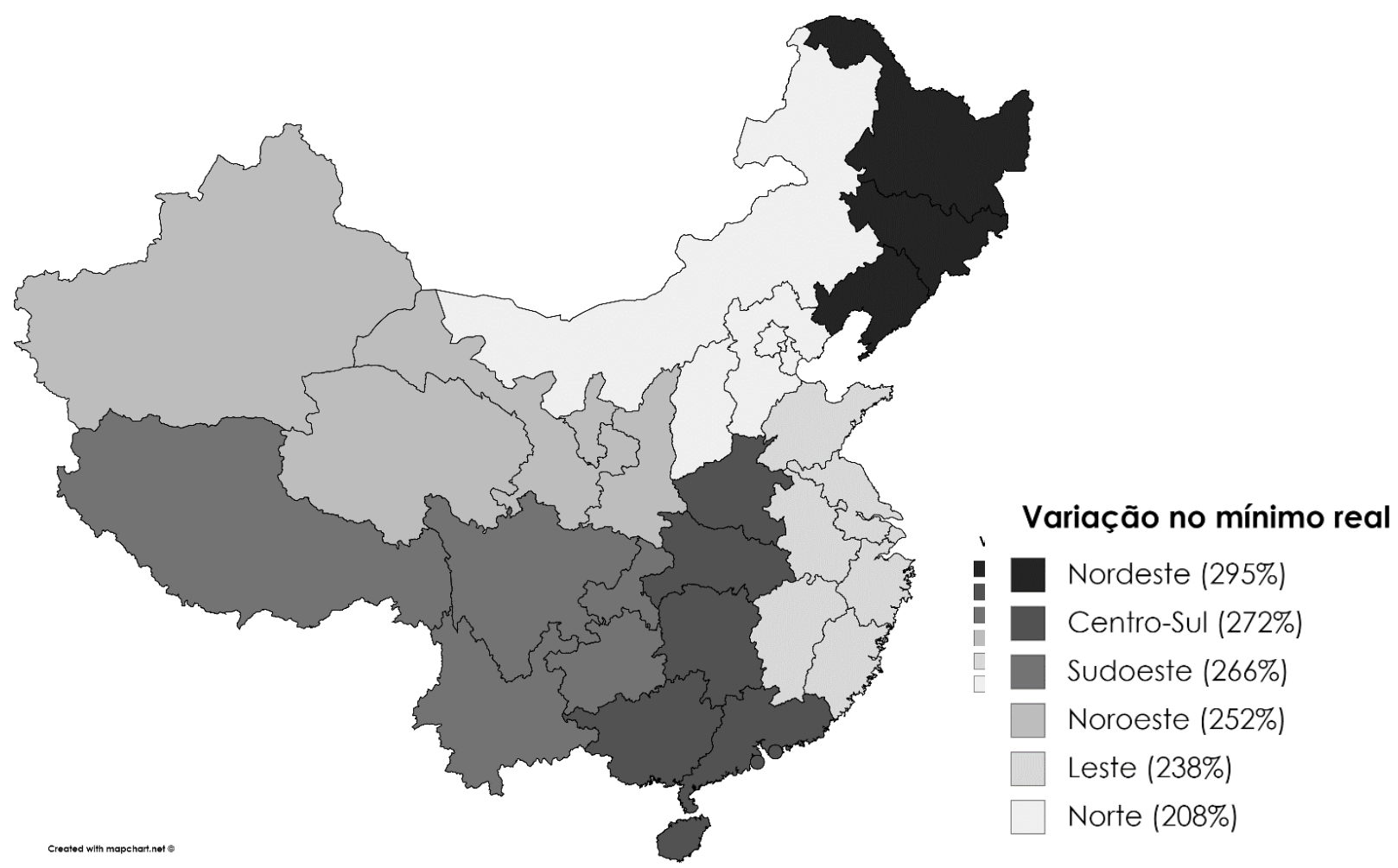

Fonte: Elaboração própria a partir de CEIC data 


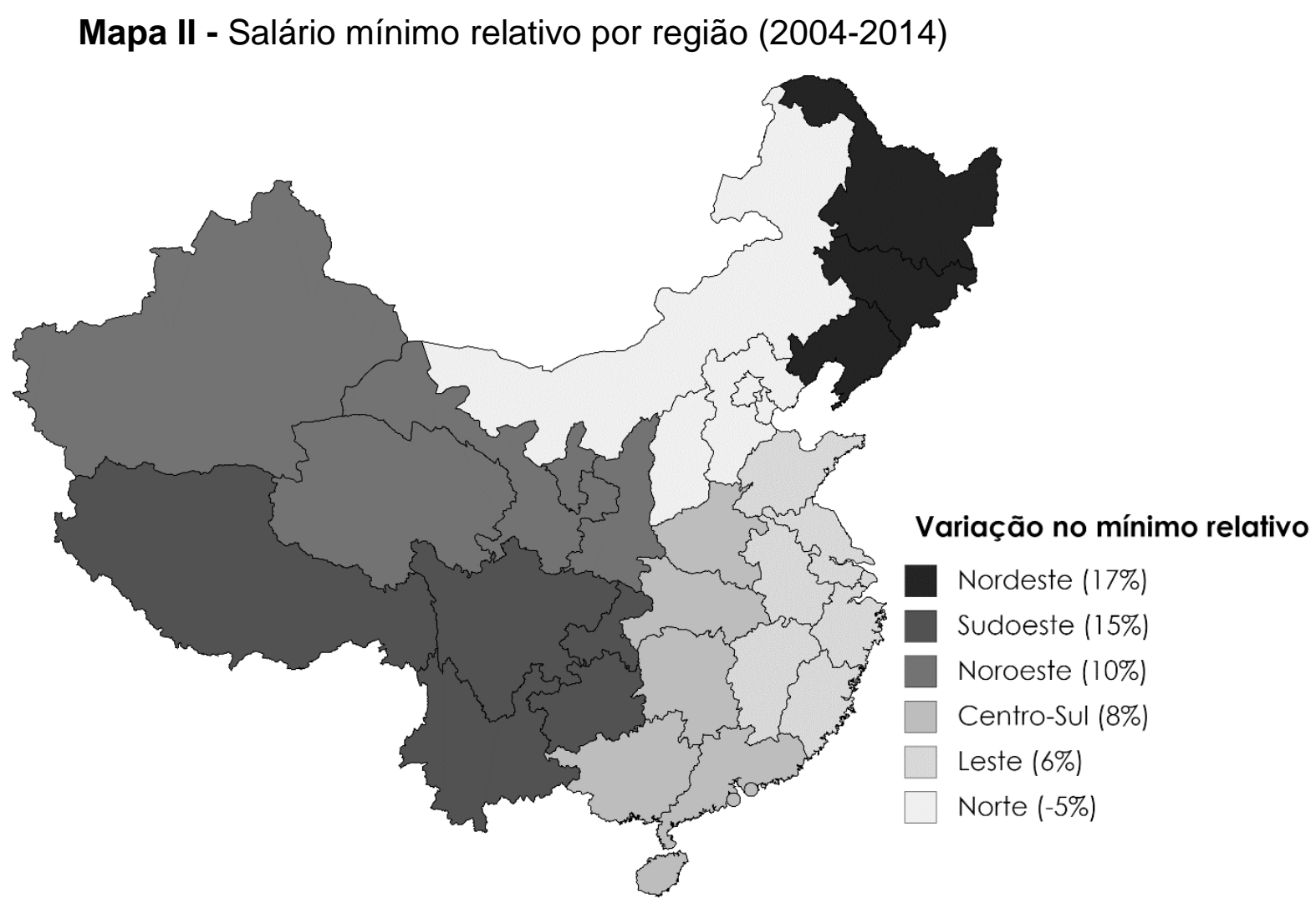

Fonte: Elaboração própria a partir de CEIC data

Mapa III - Salário mínimo relativo por região (2014-2018)

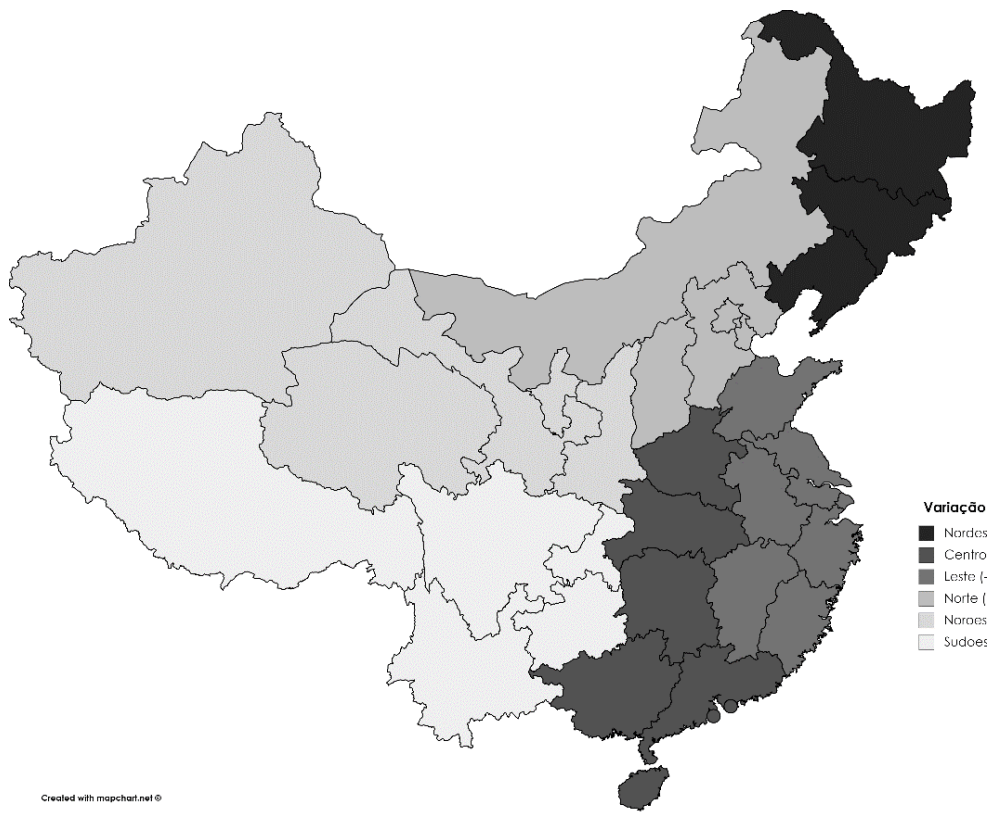

Fonte: Elaboração própria a partir de CEIC data
Variação no mínimo relativo

Nordeste $(-6 \%)$

Centro-Sul (-10\%)

Leste $(-11 \%)$

Norte (-13\%)

Noroeste (-16\%)

Sudoeste $(-21 \%)$ 
Do ponto de vista distributivo, os aumentos do mínimo relativo ao médio sobretudo em regiões menos desenvolvidas podem estar por trás da redução nas desigualdades de renda entre as províncias, algo que vigorou até 2015 ou durante a vigência da "sociedade harmoniosa". Nesse período, a política de salário mínimo foi não só um dos elementos de proteção social que ganhou espaço nas políticas nacionais, mas também uma medida redistributiva. A partir de 2015, acompanhando a reversão na política de salário mínimo, as desigualdades passaram a crescer novamente na China (ver NOGUEIRA, GUIMARÃES, BRAGA, 2019 para uma discussão sobre desigualdades na China).

Da mesma forma, também compreendemos a política de salários mínimos como um instrumento de mediação dos conflitos capital-trabalho durante a "sociedade harmoniosa". No período de 2004 até 2008, com greves se tornando comuns nos polos industriais (HUI, 2014), o governo central conduziu uma valorização dos salários mínimos provinciais para que eles acompanhassem o salário médio. Em 2008, com a crise financeira atingindo fortemente as exportações industriais chinesas, o governo central coordenou um congelamento dos salários mínimos. No entanto, a partir de 2010, como forma de estimular a recuperação econômica e minimizar o conflito capitaltrabalho, observou-se uma forte valorização do salário mínimo. Como essa política de contenção do conflito distributivo parece ter contribuído no sentido de reduzir as disparidades de renda entre as regiões, de fato registrou-se um esforço de redução das desigualdades de renda do trabalho por parte das autoridades chinesas em uma compreensão ampliada do Estado de Bem-Estar chinês como instrumento de coesão social.

Durante os anos iniciais do "sonho chinês", o uso da política de salário mínimo como forma de minimizar as desigualdades desapareceu. Pelo contrário, registrou-se uma forte queda do salário mínimo frente ao salário médio. Ao mesmo tempo, esse é um período em que a mudança para um padrão de acumulação puxado pela inovação tecnológica e pelo consumo interno se tornou o objetivo central da política de desenvolvimento. Isso sugere que a política de salário mínimo tem sido usada na China na mediação dos conflitos capital/trabalho e no estabelecimento de um Estado de bemestar social ampliado, mas não do ponto de vista do seu papel na consolidação de um novo padrão de crescimento. Esse resultado dialoga com a constatação de que há uma 
mudança institucional muito profunda na forma pela qual os conflitos sociais internos são enfrentados a partir do início do período do sonho chinês com Xi Jinping.

\section{Conclusão}

De fato, a articulação entre a consolidação do jovem mercado de trabalho chinês e uma política oscilante de salários mínimos em um mercado de trabalho fortemente aquecido aponta para a centralidade do papel do Estado como elemento característico do padrão de crescimento chinês. Essa constatação dialoga profundamente com a abordagem histórico-institucional de Polanyi, apontando que os mercados de trabalho modernos são profundamente dependentes de políticas de regulação da mercadoria fictícia que é o trabalho de forma a possibilitar a acumulação de capital. Analisando as transformações institucionais que consolidaram esse mercado desde sua criação até os dias contemporâneos, este artigo proporciona uma lente crítica em relação à evolução dos salários mínimos na China desde o estabelecimento da "sociedade harmoniosa" do ex-presidente Hu Jintao e durante o atual "sonho chinês" de Xi Jinping.

A partir da estimação dos valores nacionais e provinciais do salário mínimo chinês, é possível medir a relevância do salário mínimo como ferramenta de reequilíbrio da distribuição de renda nacional no período da "sociedade harmoniosa", enquanto durante "sonho chinês" houve uma perda real sensível dos salários mínimos frente aos salários médios. Assim, a função mais importante da política de salário mínimo no primeiro período foi a de reequilibrar a distribuição de renda nacional. Diante de uma valorização mais acentuada do salário mínimo nas regiões mais pobres em comparação às mais ricas, observa-se nos dados aqui disponíveis uma tentativa de reduzir a heterogeneidade regional das remunerações - uma espécie de cathing-up salarial puxado pelo Estado.

Por um lado, a política de valorização dos salários mínimos a partir de 2004 simboliza a importância da regulação dos mercados de trabalho na busca por uma "sociedade harmoniosa". Pelo outro, durante o período do "sonho chinês" a questão distributiva parece não ter sido dominante nas políticas públicas nacionais. Isso sugere que a política de salário mínimo tem sido usada na China na mediação dos conflitos capital/trabalho e no estabelecimento de um Estado de bem-estar social ampliado, mas não do ponto de vista do seu papel na consolidação de um novo padrão de 
crescimento. Esse resultado dialoga com a constatação de que há uma mudança institucional muito profunda na forma pela qual os conflitos sociais internos são enfrentados a partir do início do período sob Xi Jinping e deve ser aprofundado em uma agenda de pesquisa futura.

\section{Referências}

AGLIETTA, M.; BAl, G. China's 13th Five-Year Plan: In Pursuit of a "Moderately Prosperous Society". CEPII Policy Brief, n. 12, 2016.

BRANDT, L.; HOLZ, C. A. Spatial price differences in China: Estimates and implications.

Economic Development and Cultural Change, v. 55, n. 1, p. 43-86, 2006.

BUGRA, A.; AGARTAN, K. Reading Karl Polanyi for the Twenty-First Century: Market

Economy as a Political Project. New York: Palgrave Macmillan US, 2007.

CAHUC, Z. Labour Economics. Cambridge MA: MIT Press, 2004.

CEIC. China Standard of Monthly Minimum Wage. Disponível em:

$<\mathrm{https}: / /$ www.ceicdata.com/pt>. Acesso em: 10 out. 2018.

CHAN, C. K. C.; HUI, E. S. I. The development of collective bargaining in China: From collective bargaining by riot to party state-led wage bargaining. China Quarterly, n. 217, p. 221-242, 2014.

CHINA BRIEFING. A Guide to Minimum Wages in China in 2018. Disponível em: $<$ http://www.china-briefing.com/>. Acesso em: 10 out. 2018.

CHINA ECONOMIC REVIEW. "Chinese Wages are Higher than Brazil, Mexico", February, 27, 2017. Disponível em: <https://chinaeconomicreview.com/chinese-wages-higher-brazil-mexico/>. Acesso em: 03 jul. 2020.

DU, Y.; PAN, W. Minimum wage regulation in China and its application to migrant workers in the urban labour market. China and World Economy, vol. 17, n. 2, pp. 79-93, 2009.

H. HERR; KAZANDZISKA, M. The theoretical debate about minimum wages. GLOBAL LABOUR UNIVERSITY WORKING PAPERS, v. 6, n. June 2009, 2009.

HEISE, A. Reconciling facts with fiction: Minimum wages in a post-Keynesian perspective. Hamburg.

ILO. Update on minimum wage developments, 2009.

KARL POLANYI. A Grande Transformação. 2. ed. Rio de Janeiro: Editora Compus Ltda, 2000.

KAUFMAN, B. E. . INSTITUTIONAL ECONOMICS AND THE MINIMUM WAGE : BROADENING THE THEORETICAL AND POLICY. v. 63, n. 3, p. 427-453, 2010.

LEE, S.; SOBECK, K. Low-wage work: A global perspective. International Labour Review, v. 151, n. 3, 2012. 
KNIGHT, J.; SONG, L. Towards a Labour Market in China. Oxford University Press, 2005.

LEMOS, S. Minimum wage effects in a developing country is. Labour Economics, v. 16, n. 2, p. 224-237, 2009.

LIANG, Z.; APPLETON, S.; SONG, L. Informal employment in China: Trends, Patterns and Determinants of Entry. IZA Discussion Paper Series, n. 10139, 2016.

MEDEIROS, C. Padrões de investimento, mudança institucional e transformação estrutural na economia chinesa. Padrões de desenvolvimento econômico (1950-2008): América Latina, Ásia e Rússia. Brasília: CGEE.

MEDEIROS, C. A influência do salário mínimo sobre a taxa de salários no Brasil na última década. Economia e Sociedade, v. 24, n. 2, p. 263-292, 2015.

MEDEIROS, C.; NOGUEIRA, I. Uma abordagem estruturalista das desigualdades de renda da China Contemporânea. Revista Tempo do Mundo, v. 3, n. 3, 2011.

NAUGHTON, B. The Chinese Economy: Transitions and Growth. Cambridge, MA: MIT Press, 2007.

NOGUEIRA. I. Desenvolvimento Econômico, Distribuição de Renda e Pobreza na China Contemporânea. Tese de doutorado, Instituto de Economia, UFRJ, 2011.

NOGUEIRA. I. Desigualdades e políticas públicas na China: investimentos, salários e riqueza na era da sociedade harmoniosa. In: Cintra, Silva e Pinto. China em transformação: dimensões econômicas e geopolíticas do desenvolvimento. Brasília: IPEA, 2015.

NOGUEIRA, I.; GUIMARÃES, J.V; BRAGA, J.P. Inequalities and Capital Accumulation in China. Revista de Economia Política, vol. 39, n.3, 2019.

NOGUEIRA, I.; BACIL, F.; GUIMARÃES, J.V. A Caminho de um Estado de Bem-Estar Social na China? Uma análise a partir dos sistemas de saúde e educação. Economia e Sociedade, vol. 29, n.1, 2020.

PATON, J. Labour as a (Fictitious) commodity: Polanyi and the capitalist "market economy". Economic and Labour Relations Review, v. 21, n. 1, p. 77-88, 2010.

PIORE, M. Unemployment and Inflation: Institutionalist and Structuralist views. New York: M. E. Sharpe, Inc., 1979.

SECURITY, M. of L. and S. Provisions on Minimum Wages. Disponível em: <http://www.asianlii.org/cn/legis/cen/laws/pomw308/>. Acesso em: 10 out. 2018.

SICULAR, T.; YUE, X.; GUSTAFSSON, B.; Li, S. The Urban-Rural Income Gap and Inequality in China. Review of Income and Wealth, vol. 53, n. 1, 2007.

WAN, G. Inequality and Growth in Modern China. Oxford University Press, 2008.

XING, C.; XU, J. Regional variation of the minimum wages in China. IZA Journal of Labor and Development, vol. 5, n. 1, 2016. 


\section{NOTAS DE AUTOR}

\section{CONTRIBUIÇÃO DE AUTORIA}

João Pedro Braga - concepção, coleta de dados, análise de dados, elaboração do manuscrito, revisão e aprovação da versão final do trabalho.

Isabela Nogueira - concepção, análise de dados, elaboração do manuscrito, revisão e aprovação da versão final do trabalho.

FINANCIAMENTO

Bolsa de produtividade de pesquisa do CNPq.

\section{CONSENTIMENTO DE USO DE IMAGEM}

Não se aplica.

\section{APROVAÇÃO DE COMITÊ DE ÉTICA EM PESQUISA}

Não se aplica.

\section{CONFLITO DE INTERESSES}

Não se aplica.

\section{LICENÇA DE USO}

Este artigo está licenciado sob a Licença Creative Commons CC-BY. Com essa licença você pode compartilhar, adaptar, criar para qualquer fim, desde que atribua a autoria da obra.

\section{HISTÓRICO}

Recebido em: 20-09-2020

Aprovado em: 13-10-2020 